\title{
A ESTIMULAÇÃO RUSSA NO FORTALECIMENTO DA MUSCULATURA ABDOMINAL
}

\author{
Russian stimulation in strengthening abdominal muscle
}

Evelyne Patrícia Fernandes LIMA, Geruza Baima de Oliveira RODRIGUES

Trabalho realizado no curso de Especialização em Fisioterapia Dermatofuncional da Faculdade Christus, Fortaleza, CE, Brasil.
RESUMO - Introdução - A flacidez muscular surge com maior frequência nas mulheres, o que causa fator ruim para a estética corporal. Objetivo - Analisar os resultados da corrente russa no fortalecimento da musculatura abdominal. Métodos - Revisão bibliográfica com base nas publicações acessíveis pelas seguintes bases de dados: Medline/Pubmed, Scielo, Lilacs com cruzamento dos descritores corrente russa, flacidez, abdômen. O uso da eletroestimulação age tanto sobre as fibras brancas, que respondem pela velocidade, como também sobre as fibras vermelhas dado à sua sustentação, e ainda sobre as fibras intermediárias. Conclusão - Os dados publicados mostram a satisfação e êxito do tratamento, enfatizando que a corrente russa favorece o aumento da hipertrofia e força muscular.

Abdômen.

Estimulação física.

\section{Correspondência:}

Geruza Baima de Oliveira Rodrigues,

e-mail: geruzabaima@hotmail.com

Fonte de financiamento: não há

Conflito de interesses: não há

Recebido para publicação:

Aceito para publicação:

HEADINGS - Physical stimulation.

Abdomen.
ABSTRACT - Introduction - Muscle weakness appears most often in women, the factor that causes bad esthetics. Objective - To analyze the results of the Russian current strengthening the abdominal muscles. Methods - Literature review based on publications available in the following databases: Medline / Pubmed, Scielo, Lilacs with crossing headings Russian current, sagging, abdomen. The use of electrical stimulation acts both on the white fibers, which account for the speed, but also on the red fibers given their support, and on intermediate fibers. Conclusion - The data published show the satisfaction and success of treatment, emphasizing that the Russian current promotes increase of muscle strength and hypertrophy.

\section{INTRODUÇÃO}

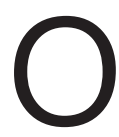
desenvolvimento da fisioterapia dermatofuncional veio de encontro ao novo conceito de beleza do século $X X$, em que principalmente as mulheres começaram a analisar suas imagens corporais e lutar contra aqueles excessos gordurosos que resistiam às dietas, às ginásticas, assim como começaram a se preocupar com os distúrbios estéticos associados às doenças estéticas, como a flacidez muscular ${ }^{20}$. Esta flacidez atua diretamente nos tecidos adjacentes, causando a perda da "intimidade" entre os tecidos e facilitam o acúmulo de gorduras em áreas flácidas ${ }^{14}$.

A corrente russa, desde que foi apresentada por Kots, por volta de 1977, como um estimulador muscular elétrico para aumentar o ganho de força, evoluiu. Atualmente, pode oferecer frequência média de 2.000 a $10.000 \mathrm{~Hz}$, com pulso podendo variar de 50 a 250 microssegundos ${ }^{5}$.

De acordo com Antonio2, "a estimulação russa foi criada para preencher uma lacuna no tratamento estético onde várias técnicas, como a plástica, tratavam a celulite, a gordura localizada e a flacidez da pele".

O presente artigo tem como objetivo analisar os resultados da corrente russa no fortalecimento da musculatura abdominal. 
MÉTODO

Revisão bibliográfica com base nas publicações acessíveis pelas seguintes bases de dados: Medline/ Pubmed, Scielo, Lilacs com cruzamento dos descritores corrente russa, flacidez, abdômen.

\section{Sistema muscular}

O tecido muscular tem origem mesodérmica, é geralmente dividido em três tipos: esquelético, cardíaco e liso. O músculo esquelético constitui a grande massa da musculatura somática, geralmente ele não se contrai na ausência de estimulação nervosa e, em geral, está sob o controle voluntário. O músculo cardíaco é funcionalmente sincicial e contrai-se ritmicamente, na ausência de estimulação nervosa. E o músculo liso é involuntário e o estímulo para a contração do mesmo é controlado pelo sistema nervoso vegetativo ${ }^{8,24}$.

O sistema muscular é o principal responsável pelos movimentos do corpo humano. Este é constituído por células alongadas que contêm grande quantidade de falimentos citoplasmáticos, responsáveis pela contração. As células musculares têm origem mesodérmica e sua diferenciação ocorre principalmente devido a um alongamento gradativo, com simultânea síntese de proteínas filamentosas ${ }^{11,21}$.

O corpo humano contém mais de quatrocentos músculos esqueléticos voluntários, os quais representam entre 40 a $50 \%$ do peso corporal total. O músculo esquelético tem três funções principais: produção de força para a locomoção e respiração; produção de força para a sustentação postural; e produção de calor durante a exposição ao frio ${ }^{23}$.

Da mesma maneira que os neurônios, as células musculares podem ser excitadas química, elétrica ou mecanicamente para produzirem um potencial de ação que se propaga ao longo de suas membranas celulares. Ao contrário dos neurônios, ela contém proteínas contráteis e um mecanismo contrátil que é ativado pelo potencial de ação ${ }^{3}$. O tecido muscular possui as propriedades da irritabilidade, contratilidade, extensibilidade e elasticidade. Nenhum outro tecido no corpo possui todas estas características ${ }^{13,19}$.

O músculo esquelético é constituído por diferentes tipos de tecidos, como células musculares, sangue, tecido nervoso e os diversos tipos de tecido conjuntivo. Entre os tecidos conjuntivos existentes, está a fáscia, que tem a finalidade de fixar os músculos individuais no lugar e separados entre $\mathrm{si}^{12,23}$.

A maioria dos músculos esqueléticos se inicia e termina em tendões e as fibras musculares estão dispostas em paralelo entre as terminações tendinosas, de modo que a força de contração das unidades é aditiva ${ }^{3}$.

Asfibrasmuscularessediferenciamestruturalmente, histoquimicamente e metabolicamente, e assim podem ser classificados em duas categorias principais: as fibras tipo I (fibras de contração lenta) e as fibras tipo II (fibras de contração rápida). A maioria dos grupos musculares dispõe de uma combinação igual de fibras tipo I e tipo II, embora alguns grupos predominem as fibras de contração lenta ou fibras de contração rápida. Vários fatores podem influenciar a quantidade do tipo de fibra existente, dentre eles a genética, níveis hormonais no sangue e prática de exercícios ${ }^{23}$.

A parede abdominal torna-se flácida, e as vísceras aos poucos voltam à posição de origem. No pós-parto imediato é possível evidenciar a diástase dos músculos reto-abdominais com a parede abdominal composta de pele, tecido subcutâneo, fáscia e peritônio. A recuperação da tonicidade da musculatura da parede abdominal, distendida pelo útero gravídico, ocorre em média de seis semanas do pós-parto, lenta e às vezes imperfeitamente ${ }^{17}$.

Conforme Dangelo e Fattini ${ }^{8}$, os músculos oblíquos abdominais (externo e interno) cumprem a função de interligação entre o tórax e a pelve.

O músculo oblíquo interno, origina-se na metade lateral do ligamento inguinal, 2/3 anteriores da linha intermediária da crista ilíaca e da fáscia toracolombar. O feixe muscular tem uma disposição irradiada em leque a partir das suas origens, sendo a sua direção geral para cima e para frente ${ }^{8}$.

\section{Flacidez muscular}

A pele é um material biológico de comportamento viscoelástico (com capacidade de deformar-se frente à pressão exercida contra o tecido). Existe relação entre a resistência interna do material em relação à carga e seu próprio alongamento. Existem duas fases: a elástica e a plástica. A elástica, ou seja, a tensão é diretamente proporcional à habilidade do tecido de resistir à carga. Nesta fase, se a carga for retirada, o tecido retorna imediatamente à dimensão anterior. Porém se o limite elástico for ultrapassado (fase de flutuação) não haverá o retorno às características originais do tecido. A fase plástica caracteriza-se pela deformação permanente ${ }^{10}$.

A flacidez é uma "sequela" causada por vários episódios ocorridos ao longo dos anos como a inatividade física, o emagrecimento demasiado, o envelhecimento, dentre outros. Nesses casos os músculos tornam-se flácidos dado essas circunstâncias. A musculatura perde a tonicidade e sem contornos definidos as fibras musculares tornam-se atrofiadas e flácidas ${ }^{10}$.

A flacidez muscular refere-se à diminuição do tônus muscular, estando o músculo pouco consistente. Ela pode apresenta-se de duas formas distintas: a flacidez muscular e a de pele. É muito comum que os dois tipos apareçam associados, dando um aspecto ainda pior às partes do corpo afetadas pelo problema. Os músculos ficam flácidos principalmente por causa da falta de exercícios físicos. Se eles não são solicitados, as fibras musculares ficam hipoatrofiadas e flácidas ${ }^{15}$.

A definição da flacidez estética é tema de 
discussão, uma vez que a flacidez da pele e a hipotonia muscular são considerados por alguns como entidade única ao passo que para outros são independentes ${ }^{10}$.

O hormônio feminino faz com que as mulheres acumulem mais gordura no corpo. Por razão da variação hormonal, há diminuição do colágeno e da elastina, fibras que dão sustentação à pele e diminuição nos líquidos da pele ${ }^{25}$.

Além da vida sedentária ou dos distúrbios na pele, há ainda um outro fator que determina a existência ou não de flacidez no corpo: a predisposição genética. Devido à maior propensão genética, alguns indivíduos têm a estrutura da pele alterada, com diminuição ou alteração das fibras de colágeno e elastina ${ }^{26}$.

A flacidez propriamente dita é provocada pela perda de elementos do tecido conjuntivo, como fibroplastos, elastina e colágeno. Esta perda faz com que a rede de elementos se torne menos densa, tirando a firmeza entre as células. O problema da flacidez muscular e dos tecidos gera pontos antisimétricos. Os tecidos se afrouxam, caem e sofrem envelhecimento precoce $\mathrm{e}^{18,28}$.

Além dos exercícios físicos, outro recurso utilizado para o aumento da massa muscular é a eletroestimulação neuromuscular, através da corrente russa que vem ampliando seus estudos em relação à fisioterapia dermatofuncional, mostrando resultados favoráveis no tratamento da flacidez muscular ${ }^{9}$.

\section{Intervenção fisioterapêutica: corrente russa}

Conforme Agne ${ }^{1}$, "o termo estimulação russa ou corrente russa tem gerado uma série de interpretações confusas pelos seus usuários, muitas vezes proporcionada pela própria literatura ou pelos manuais que acompanham o equipamento".

A corrente russa, também conhecida como estimulação russa, é formada por trens de impulsos de corrente do tipo retangular ou senoidal, bipolar, simétrica, emitidos na frequência de 2.500 hertz modulada por uma onda que pode variar de 50 a 80 hertz ${ }^{6}$.

Na estimulação elétrica neuromuscular (EENM) de média frequência $(2.500 \mathrm{~Hz})$ a corrente russa é a mais utilizada, estimula os nervos motores, despolarizando as membranas, induzindo assim contração muscular mais forte e sincronizada, resultando em fortalecimento muscular ${ }^{16}$

Com o avanço dos programas de reabilitação, tem-se buscado recursos que minimizem a atrofia e a flacidez muscular causadas por imobilização, processos pós-cirúrgicos e sedentarismo ${ }^{4,27}$.

Uma das medidas eficazes para trabalhar a flacidez muscular é o uso da estimulação elétrica neuromuscular que, associado à cinesioterapia, tem sido um dos recursos mais utilizados no fortalecimento do músculo, assim como na prevenção de atrofias musculares 9,25.

Estudos e pesquisas mostram que a realização constante de exercícios leva as pessoas a adquirirem condicionamento físico melhor e vida mais saudável. Em decorrência dos avanços tecnológicos estudiosos, como Araújo 3 , Caetano e Pires ${ }^{7}$ aperfeiçoaram aparelhos de eletroestimulação com a finalidade de estimular e tonificar a musculatura corporal com o menor esforço físico possível.

Entretanto, o sucesso dessa terapia dependerá amplamente dos parâmetros utilizados clinicamente na eletroestimulação. Para usar a eletroestimulação neuromuscular de forma mais efetiva, o terapeuta precisa conhecer não só a condição a ser tratada, mas também todo o mecanismo que ocorre nos tecidos pelo uso da corrente elétrica, utilizando-se corretamente de todos os parâmetros de estimulação e saber quando e como regulá-los para torná-los mais convenientes à realidade do paciente ${ }^{22}$.

No contexto da fisioterapia dermatofuncional, a região abdominal é a mais solicitada pelas pacientes como regiões prioritárias a serem tratadas, com o objetivo de minimizar a flacidez muscular e a perda do tônus. A corrente russa também tem sido utilizada para tratamentos de pós-operatório em geral, recuperação das sensações de tensão muscular, disfunções posturais, instabilidade articular, analgesia e na área desportiva ${ }^{5}$.

\section{Considerações finais}

Baseado na revisão bibliográfica deste estudo percebe-se a importância de mais pesquisas a fim de analisar os efeitos da associação da eletroestimulação russa na região abdominal, para que se possa afirmar com mais afinco a sua eficácia na diminuição da flacidez e perda do tônus muscular, como também compará-la com outros métodos de fortalecimento muscular.

Conclui-se que os dados revelados mostram a satisfação e êxito do tratamento, enfatizando que a corrente russa associada favorece aos resultados satisfatórios com o aumento da hipertrofia e força muscular.

\section{REFERÊNCIAS}

1. Agne, JE. Eletrotermoterapia: teoria e prática. Santa Maria: Orium, 2006.

2. Antonio S. O uso da corrente russa para promover o fortalecimento dos músculos peitoral maior e menor. 2009. Disponível em: <http:// www.fisio-tb.unisul.br/Tccs/02b/sheila/artigoscheilaantonio.pdf>. Acesso em: 06 ago. 2010.

3. Araújo AM. Análise comparativa da efetividade da corrente russa na região glútea. Fortaleza: Faculdade Integrada do Ceará, 2009. Monografia de graduação em Fisioterapia.

4. Barbosa AR, Santarém JM, Jacob-Filho W, Marucci MFN. Efeitos de um programa de treinamento contra resistência sobre a força muscular de mulheres idosas. Rev Bras Atividade Física e Saúde 2000; 5(3).

5. Borges FS. Dermato-funcional: modalidades terapêuticas nas disfunções estéticas. São Paulo: Phorte, 2006.

6. Briel AF, Pinheiro MF, Lopes LG. Influência da corrente russa no ganho de força e trofismo muscular dos flexores no antebraço não dominante. Arq Cienc Saúde Unipar 2003; 7(3):205-210 
7. Caetano A, Pires GDL. O corpo, lugar do contato privilegiado com o mundo, sob a luz dos holofotes: reflexões sobre corpo na Educação Física a partir da Indústria Cultural e da Sociologia do Corpo. Revista Digital 2009; 14(135).

8. Dângelo JG, Fattini CA. Anatomia Humana sistêmica e Segmentar. 3. ed. Rio de Janeiro: Atheneu, 2007.

9. Evangelista AR. Estudo comparativo do uso da eletroestimulação na mulher associada com atividade física visando à melhora da performance muscular e redução do perímetro abdominal. Rev Fisioter Brasil. 2003; 4(1):49-59.

10. Guirro E, Guirro R. Fisioterapia dermato-funcional: fundamentos, recursos, patologias. 3.ed. São Paulo: Manole, 2004.

11. Junqueira LC, Carneiro J. Histologia básica. Rio de Janeiro: Guanabara Koogan, 2000.

12. Kitchen S, Bazin S. Eletroterapia de Clayton. 10.ed. São Paulo: Manole, 1998.

13. Lippert LS. Cinesiologia clínica para fisioterapeutas. 3.ed. Rio de Janeiro: Guanabara Koogan, 2003.

14. Lopes, CL. Estudo sobre a eficácia da eletroestimulação neuromuscular de média frequencia na hipotrofia muscular glútea em mulheres jovens. 2004. Disponível em: <http://www.unioeste. br/projetos/elrf/monografias/2004.../carolina\%20lopes.PDF>. Acesso em: 25 jul. 2010.

15. Lopes SC, Brongholi K. A utilização da corrente russa no tratamento da flacidez muscular abdominal. 2009. Disponível em: < http:// www.fisio-tb.unisul.br/Tccs/04a/cristiana/artigocristinasouza. pdf > . Acesso em: 25 jul. 2010.

16. Low J, Reed A. Eletroterapia explicada: princípios e práticas. 3.ed. São Paulo: Manole, 2001.

17. Machado A. Fisioterapia aplicada à Obstetrícia \& aspecto de Neonatologia: uma visão multidisciplinar. Belo Horizonte: Health, 2000.
18. Marques C. Tratamentos anti-flacidez. 2004. Disponível em: <http://www.planetadamulher.com.br;boaforma3.php.htm>. Acesso em: 25 jul. 2010.

19. Mendes LN. Estimulação elétrica muscular. 2009. Disponível em: <http://fisioterapiadesportiva.blogspot. com/2009/0 5/estimulacao-eletrica-muscular.h tml>. Acesso em: 15 ago. 2010.

20. MeyerPF, Medeiros JO, Oliveira SSG. O papel psicossocial do ambulatório de fisioterapia dermato-funcional na saúde e da população de baixa renda. Fisioterapia em Movimento, 2003; 16(4):55-61.

21. O'Sullivan SB, Schmitz TJ. Fisioterapia: avaliação e tratamento. São Paulo: Manole, 2004.

22. Orlandi, V. Corrente russa e exercício resistido no músculo glúteo máximo. Tubarão: Universidade do Sul de Santa Catarina, 2005. Monografia de graduação em Fisioterapia.

23. Power SK, Howley ET Fisiologia do exercício: teoria e aplicação ao condicionamento e ao desempenho. São Paulo: Manole, 2005.

24. Robinson AJ. Eletrofisiologia clínica: eletroterapia e teste eletrofisiológico. 2.ed. Porto Alegre: Artmed, 2001.

25. Rocha PN. O sistema neuro-hormonal. 2004. Disponível em <http://www.corpohumano.hpg.ig.com.br/ab_news_health/ noticias.htm> Acesso em: 20 jul. 2010.

26. Seixas, L. A lei da gravidade pode ser contornada se algumas técnicas de combate forem adotadas. 2004. Disponível em: <http://www.saudenarede.com.br/artigos htm>. Acesso em: 20 jul. 2010.

27. Vilela ALM. Sistema muscular. 2009. Disponível em: <http://www. afh.bio.br/sustenta/Sustenta4.asp>. Acesso em: 16 ago. 2010.

28. Weineck, J. Biologia do esporte. São Paulo: Manole, 2000. 